\title{
Self-Regulated Learning in Online-Based Teacher Education And Training Programs
}

\author{
Wawan Krismanto ${ }^{1}$, Lilik Tahmidaten ${ }^{2}$ \\ ${ }^{1}$ Department of Elementary School Teacher Education, Universitas Negeri Makassar \\ 2 Departement of Sociology, PPPPTK PKN \& IPS Ministry of Education, Culture, Research and Technology \\ email: wawan.krismanto@unm.ac.id, lilik.p4tkips@gmail.com
}

Received: 13 August 2021; Revised: 02 October 2021; Accepted: 14 December 2021

DOI: http://dx.doi.org/10.37905/aksara.8.1.413-424.2022

\begin{abstract}
The era of the coronavirus disease pandemic is increasingly driving the process of transforming teacher education and training from face-to-face to online-based. Besides having flexibility and accessibility, in practice, the transformation process has several weaknesses and challenges. One of them is a culture of self-regulated learning from the participating teachers. For this reason, the purpose of this article is to review self-regulated learning in online-based teacher education and training programs with key questions- how important is self-regulated learning in online-based teacher education and training programs? and how to facilitate the development of self-regulated learning in online-based teacher education and training programs? To answer this, we conducted a literature study of various books and previous research articles, so that the results were complete, both conceptually and empirically. As a result, self-regulated learning has become an important and strategic aspect for the success of any learner or online learning program, including online-based teacher education and training programs. For this reason, every designer, organizer and instructor need to facilitate the development of participants selfregulated learning aspects through their online learning platforms. Although it cannot be assumed that they will automatically and effectively develop their self-regulated learning skills, through deliberate design and facilitation efforts, they need to create and sustain the development of self-regulated learning skills of e-learners through rich learning experiences. Positive self-regulated learning tends to encourage the success of the online-based teacher education and training programs because teachers will give their best efforts to complete their online learning and have the potential to achieve the best results.
\end{abstract}

Keywords: Online-based teacher education, self-regulated, teacher competence, teacher training

\section{INTRODUCTION}

Online or digital learning environments have been widely used in learning at all levels of education, including in the provision of education and training in the context of developing teacher competence. Entering The era of the coronavirus disease (COVID-19) pandemic, the massive implementation of distance learning, including the transformation of teacher education and training, has shifted from face-to-face to online-based. The era of the Covid-19 pandemic has pushed for the transformation process of the implementation of education and training in the context of teacher competency development which is carried out formally by various institutions of technical implementing units of teacher education \& training in Indonesia, both under the Ministry of Education, Culture, Research and Technology and the Ministry of Religion. Quantitatively, the implementation of teacher competency development carried out informally by teacher communities is also increasingly being held for teachers in Indonesia with various online learning platforms. They are organized by teacher communities through various social media platforms such as Instagram, Meta, Telegram Groups, WhatsApp Groups. They design and implement learning activities whose focus and orientation is to improve teacher competence. This illustrates that the 
Covid-19 pandemic era has encouraged massive online learning activities among Indonesian teachers. Learning through various learning platforms/course management systems and various virtual conference platforms is easier for teachers to find, both formally and informally.

The availability of a learning environment for teachers, as described above, actually encourages teachers to re-learn and adapt to the development of learning technology. The teacher's learning experience with the online learning environment brings teachers closer to the rapidly growing digital world. The digital world directs different ways of learning to teachers as learning participants. In the context of learning, Prensky explains that participants' experiences of learning in a digital culture affect the way they acquire knowledge and manage their learning process and this concept is based on the idea that their interaction with the world of ICT will change the way that learning is carried out and felt (Prensky 2004, 2014). Thus, the interaction of teachers with the digital world in their daily lives, including in the teaching and learning process, will develop the competence of teachers regarding digital literacy, especially related to "how to learn in the digital world". In this case, Barak revealed that various forms of ICT that are integrated with learning can function as a facilitator of digital literacy, self-efficacy development, collaborative learning, concept understanding, and higher-order thinking skills (Barak 2010, 2018).

However, the big question is: in the process, what are the problems faced by teachers as e-learners that have the potential to hinder the achievement of maximum learning outcomes? In this case, Kumar explained that in online learning, there are 5 most common problems faced by learners in online learning environments (Kumar 2015), namely 1) Adaptability Struggle, in the context of teacher learning, the transition process from face-to-face teacher education and training to basic computers in virtual classrooms, creating a different learning experience for teachers. It takes time to get used to the learning/course management system and the computer-based educational methods they follow. 2) Technical Issues, many teachers in an e-learning do not have high bandwidth or strong internet connection according to the needs of the online learning they are following. 3) Computer Literacy, although teachers generally understand technology so they can manage computers well, the lack of computer literacy is a major problem among teachers, for example, unable to operate basic programs or applications needed when participating in online learning. 4) Time Management, is a difficult task for teachers as learners because online education and training require a lot of time and intensive work. In addition, although web-based learning programs have the advantage of the flexibility of place and time, teachers rarely provide specific time to follow the learning process because of their various tasks. 5) Self-Motivation, is an important requirement in a learner online learning environment. Many teachers as learners lack it. After enrolling in teacher education and training, many learners are left behind and give up, due to various difficulties that they seem unable to overcome on their own. It seems that these problems need to be addressed so that the online learning environment organized for teacher competency development can maximize the process and results. Massive online learning among teachers certainly needs to be balanced with the quality of the process and results.

For that, we need a study or analysis to discuss the problems above. In this article, we focus on the study of self-motivation, especially on the following issues: 1) 
how important is self-regulated learning in online-based teacher education and training programs? and 2) how to facilitate the development of self-regulated learning in online-based teacher education and training programs? This study is important because the skills and abilities of learners do not fully explain their learning achievement or success. This suggests that other factors, such as motivation and selfregulation, make important contributions to successful learning (Schunk 2012). Marfuah explained that one of the weaknesses and challenges in the implementation of online training is a culture of self-regulated learning, the ability to learn independently (Marfuah 2017). In addition, designers, online learning managers and instructors are urgent to understand comprehensively in facilitating self-regulated learning for teachers as learning participants. This is one of the determinants of the success of online learning. So, this study can complete a reference for designers, online learning managers and instructors in developing online learning, especially in online-based teacher education and training.

Self-regulated implementation strengthens the term of a learner to include anyone who is proactive in their learning efforts, is aware of his or her strengths and limits, and is directed by personal goals and tasks (Zimmerman 2015). Participants in online or e-learning environments are influenced by this. This kind of learner keeps a record of his progress toward his goals and reflects on his efficiency improvements. This improves their self-esteem and motivation to keep improving their learning strategies (Zimmerman 2008). Every designer, instructor, and online learning environment manager should have a reference for the kinds of approaches in learning settings that foster self-regulated learning, such as encouraging learners to set goals, use effective task strategies, monitor progress, record, learning organization, and establishing a productive work environment, and so on. Online teacher education and training programs include it.

\section{METHOD}

This research is qualitative research that is literature study or library research, namely a series of activities related to the collection of library data in the form of books, literature, notes and reports related to the problem being solved, then reading and recording and processing research materials (Nasir 2005; Zed 2008). In this research, the series of activities are related to collecting library data, reading and taking notes, then processing the appropriate and necessary information to answer the problem formulation 1) how important is self-regulated learning in online-based teacher education and training programs? and 2) how to facilitate the development of self-regulated learning in online-based teacher education and training programs?. Following its benefits, this literature study can be a preliminary study to understand more deeply the new phenomena that are the focus of research (Zed 2008:2), in this article focus is on understanding self-regulated learning online- based teacher education and training programs. The steps taken by the researcher, in this case, are: 1) exploring general ideas about research, 2) focusing on the problem that is manifested in the form of problem formulation, 3) finding information that supports the research focus, 3) confirming the research focus and organizing appropriate library materials. , 4) search and find data sources in the form of main library sources, namely books and scientific articles, 5) re-organize materials and conclusions obtained from 
data sources, 6) review information that has been analyzed and is suitable for discussing and answering the research problem formulation, 7) enrich data sources to strengthen data analysis and 8) compile research results in an article.

\section{RESULTS AND DISCUSSION Self-Regulated in Learning}

In an attempt to explore human self-control, interest in self-regulated learners as a formal research topic arose during the 1970s and early 1980s. During this era, studies on self-regulated learning evolved based on a variety of theoretical sources. Vygotsky's subsequent essays, which discussed more completely how children's inner dialogues originate from social encounters and serve as a source of self-control, were published in English around this time (Zimmerman 2015). Goal setting, planning, learning strategies, self-reinforcement, self-reflection, and self-study are all examples of self-regulated learning, which includes metacognitive processes, motivation, and personal behaviour to gain information and skills. The self-regulated learning perspective shifts the focus of educational analysis away from the learner's ability to learn and the learning environment as a fixed thing and toward a process begun by the student themself by identifying the best strategy and setting for their learning. This view recognizes learning as a proactive activity that learners engage in rather than an unexpected occurrence that happens to them as a result of their learning experience (Zimmerman 2015). As a result, self-regulated learning is defined as learners' feelings, thoughts, and actions that are systematically directed toward achieving their goals. Self-regulation, according to Zimmerman's theory, is a result of a person's personality, behaviour (i.e., motivational, cognitive, and emotional components), and the external environment. This is a reference to Albert Bandura's social cognitive theory, in which humans are viewed as the result of an interdependent causal structure having personal, behavioural, and environmental aspects. Unlike behaviourism, which stresses the environment's effect on human behaviour, social cognitive theory views human behaviour as being determined by reciprocal determinism. This indicates that the individual's biological and internal behavioural layouts, as well as the external environment, interact. In other words, self-regulation is viewed as a triadic process including personal, behavioural, and environmental (Zimmerman 2015).

Various models of self-regulated learning, including those suggested by experts, may be found in the literature. Pintrich et al., on the one hand, define self-regulated learning as a goal-oriented process with a focus on its constructive or self-generated nature. Cognitive, motivational, emotional, and social elements all play a significant role in monitoring, regulating, and controlling one's learning in these theories (Pintrich et al. 2001). On the other hand, is defined by Winne as a metacognitive process aimed at adapting the usage of cognitive tactics and strategies to tasks (Winne 2015). Despite the disparities between models, there appears to be an accord that the self-regulated learning process involves several periods or stages. Self-regulated learning, for example, is divided into four stages, according to Pintrich: thinking forward, monitoring, controlling, and reflecting (Pintrich 2000). Zimmerman highlights that the whole self-regulated learning process is cyclical since thoughts, feelings, and actions are cyclically adjusted through feedback to achieve personal goals (Zimmerman 2015). 
Self-regulated learning can be described by awareness of someone's thoughts, the usage of strategies, and continuing motivation. Self-regulated learning not only considers thinking, but also supports individuals in designing, selecting learning strategies, and analyzing their appearance to solve problems effectively. Several attributes are similar in the expert's definitions, even though the experts' characteristics are considerably different. Three similar characteristics contained in the definition of self-regulated learning are: (1) Individuals design their learning according to the needs and objectives of the individual concerned, (2) Individuals choose strategies and implement their learning designs; then (3) individuals monitor their learning progress, evaluate their learning outcomes and compare them with certain standards. The characteristics contained in self-regulated learning describe the state of a highly individual personality and contain a metacognitive process in which individuals consciously design, implement and evaluate their learning and themselves carefully. Study habits as above will cumulatively foster a strong desire to learn from the individual concerned. The next stage of development will form individuals who are tough, tenacious, responsible, have high achievement motives and help individuals achieve their best results.

The self-regulated learning approach focuses on controlling cognition, motivated behaviour, and setting. Students create learning goals and then try to monitor, regulate, and manage their cognition, motivation, and activity while being controlled and restricted by the goals and contextual meanings in their environment (Pintrich 2000). Pintrich had previously proposed a four conceptual framework for researching self-regulated learning, which included planning, goal setting, control, and reflection. In this approach, self-regulation is defined as the learner's ability to be active in the learning process to achieve the stated goals, as measured by cognitive, motivational, and metacognitive factors (Pintrich 1999).

\section{The Importance of Self-Regulated Learning in an Online Learning Environment}

Along with the massive implementation of online learning, a major challenge arises for learners, namely their ability to learn effectively in a rapidly growing digital environment. This is because digital learning environments are not unlike traditional learning settings. The digital learning environment demands the involvement of each individual who learns. This is due to the lack of structured guidance and support that has been considered replaced by features in digital technology. To encourage effective learning in such an environment, every learner must be trained in mastering key self-regulated learning strategies (Winters, Greene, and Costich 2008). In other words, when someone is in the learning process in the current era, the opportunity, speed, breadth and depth of a person in carrying out the learning process are not completely under the control of the educator. But gradually shifted on himself. Thus, when undergoing the learning process, students will control themselves in following the various stages of learning that are undertaken and manage themselves during the learning process or termed self-regulated learning abilities. Self-regulated learning is an active and constructive process in which learners determine goals for their learning based on past experiences and contextual features of the current environment (Pintrich 2000).

Furthermore, it has been shown that learners with effective self-regulated learning practices are better prepared to handle the problems of a fast-changing environment in the context of 21st-century learners (Cheng and Chau 2013). Self-regulated learners are individuals who can use cognitive, metacognitive, emotional, and motivational 
processes to increase their performance (potential) of achieving their learning goals (Pintrich 2004; Zimmerman 2015). In addition to these psychological processes, selfregulated learners can adjust their behaviour to take the steps necessary to attain their learning goals and keep them going until they succeed. This behaviour change is represented in a sequence of actions or strategies in which the learner sets goals, monitors, regulates, and controls them, and is guided and controlled by those goals and the learning environment's contextual features (Pintrich 2000). In addition, the capacity of learners to choose and adapt their learning strategies according to the learning context is the key to engaging in self-regulated learning (Winne 2015).

Dettori and Persico describe that when the learning environment is highly structured, always interesting and focused on acquiring skills or simple tasks, learners tend not to need or have high self-regulation to be successful in such an environment (Dettori and Persico 2011). On the other hand, self-regulation is necessary when: 1) the environment is focused on complex and multi-step tasks in which strategies and possible solution outcomes are not known in advance (so the learner must plan and monitor their performance during learning), 2) it is easy for the learner to become distracted, lose interest, or forget the main purpose of the task, 3) the task requires the use of strategies (e.g., note-taking) to overcome thought processing limitations, and 4) the learner must engage in self-beneficial behaviour (e.g., planning, monitoring, use of strategies, etc.), without guidance, pressure, or encouragement from others. In such an environment, learners who engage and demonstrate self-regulated learning skills and behaviours tend to be much more likely to succeed, than learners who are not involved and exhibit self-regulated learning abilities and behaviours.

Then, researchers who studied self-regulated learning explained that learners who were trained in self-regulated learning could set goals, demonstrate learning goals, mastery and high confidence in their learning, and attribute dissatisfaction with the results achieved to their learning strategy incompatibility or failure. to manage learning resources effectively (Pintrich 2004; Zimmerman 2008). On the other hand, learners with less skilled self-control, often fail to set goals and tend to pursue goals that keep them away from the task, show low self-confidence in learning and attribute unsatisfactory performance, especially from external sources, such as instructors or learning design. which is not effective. In line with the development of information and communication technology in the context of education, the theory underlying selfregulated learning has also shifted its attention to the importance of technology for learning. This then prompted researchers to introduce a conceptual model for selfregulated learning in an online context by elaborating components such as resource use, strategy use, motivation, planning and monitoring (Kizil and Savran 2016). Therefore, the most important task for educators and instructional designers today is to develop an effective e-learning environment and system to support learners to become selfregulated learners. According to Lock, online teaching (e-learning) is more than just presenting content and assessing the knowledge gained, but on the contrary, the involvement of learners in the process and content of learning by using various skills, one of which is self-regulation skills. For this reason, educators need to be able to develop learning design skills that support learners to develop self-regulation skills, especially in an online environment (Lock, Eaton, and Kessy 2017). 
Wang said that that in an e-learning environment, learners must have strong selfcontrol and independence; else, their e-learning efficacy would suffer. If the e-learning environment supports learners to develop strong self-regulation skills, they will be more likely to appreciate the effectiveness of their learning (Wang 2011). Furthermore, he underlined that, while self-regulated learning is essential in both conventional and elearning contexts, he believes it is more essential in e-learning environments than in traditional learning environments. Then Zimmerman claims that the learner's selfregulated learning ability may be taught and enhanced by the learner's efforts. They propose that teachers may help students engage in self-regulated learning by providing suitable tools and learning opportunities, as well as encouraging them to employ selfregulated learning strategies until they have experienced and felt the benefits of selfregulated learning (Zimmerman 2015). Studies from Anderton show that online classrooms offer opportunities for instructors to encourage self-regulated learning strategy skills in learners (Anderton 2006).

Self-regulated learning strategies may be implemented in individual or collaborative activities, according to Dettori et al., online access to the social environment has a positive impact on learners' self-regulated learning skills, such as cognitive and metacognitive reflection (Dettori, Giannetti, and Persico 2006). Dabbagh $\&$ Kitsantas further propose that a web-based learning environment for communication and collaboration can help learners build self-regulated learning abilities, which will improve their performance in online learning environments. LMSs, such as Blackboard, Moodle, and Desire2Learn, combine several features into a single interface that may be customized to help students acquire self-regulated learning abilities (Dabbagh and Kitsantas 2005). In this case, Johnson explained that the technology in the digital learning environment (DLE) that currently exists can encourage the implementation of the self-regulated learning cycle phase in learning, including understanding tasks and then planning, strategizing and evaluating the progress of completing the required tasks. Also in DLE, technology systems, curriculum materials and teaching procedures seek to improve self-regulated learning by providing mechanisms and opportunities for learners to clarify their understanding of tasks, develop effective plans, select strategies and monitor mastery of learning outcomes (Johnson and Davies 2014).

In their study, Dabbagh \& Kitsantas explains that learners argue that collaboration and communication tools have supported goal setting, seeking help, and planning and time management; content creation and self-evaluation, task strategy and goal setting; features on hypermedia support task strategies; and administrative features support selfmonitoring and help-seeking (Dabbagh and Kitsantas 2005). The book Learning Management System Technologies and Software Solutions for Online Teaching: Tools and Applications explain that LMSs include synchronous chat, asynchronous discussion forums, internet-mail systems, whiteboards, online journals \& blogs, wikis, grade books, course calendars, announcements, personal notes, and portfolios, among other features and tools that can help with the implementation of self-regulated learning (Kats 2010).

Meanwhile, Carneiro revealed that technological innovation has made it possible to design technology-enhanced learning environments, many of which have the potential to foster self-regulated learning (Carneiro et al. 2011). Dettori and Persico in the book Fostering Self-Regulated-Learning through ICT assert that it is true that the 
development and utilization of self-regulated learning skills can contribute to successful learning in an online learning environment, but it is also true that an online learning environment can be an ideal setting for individuals to acquire self-regulated learning skills and take greater control and responsibility for their subsequent learning (Dettori and Persico 2011).

In line with the development of information and communication technology in the context of education, the theory underlying self-regulated learning has also shifted its attention to the importance of technology for learning. This then prompted previous researchers to introduce a conceptual model for self-regulated learning in an online context by elaborating components such as resource use, strategy use, motivation, planning and monitoring (Kizil and Savran 2016). Nearly 3 decades of research has presented optimistic conclusions about the effectiveness and feasibility of interventions focused on self-regulated in the school context, showing that learners who display more adaptive self-regulated strategies exhibit better learning and higher motivation to learn (Pintrich 2000). Perels et al. show that integrating self-regulated learning with problem-solving learning is very effective in improving self-regulation and learner achievement, the ability of self-regulated learners can be affected by a relatively short intervention (Perels, Gürtler, and Schmitz 2005). Another study concluded that integrating selfregulated learning functions into WebQuest-based language instruction can improve selfregulated learning behaviour in language learning (Hsiao et al. 2012). Other findings show that the profile of the use of technology used by most of the learning participants shows that there is a significant positive correlation between self-regulated learning facilitated by ICT and the academic performance of learners, there is a positive attitude of learners towards the role of ICT tools in facilitating the achievement of their language learning goals, there is a positive attitude towards the role of ICT in facilitating the achievement of their language learning goals positive towards the use of ICT tools as resources in language learning (Kizil and Savran 2016). Another study shows that learners who have high self-regulated learning show stronger perceptions of $\mathrm{CoI}$ and achieve higher effective outcomes, compared to learners who have low self-regulated learning. This finding confirms that self-regulated learning can play an important role in the inquiry community framework (Cho, Kim, and Choi 2017). Researchers who studied selfregulated learning explained that self-trained learners can set goals, demonstrate mastery learning goals and high self-confidence in their learning, and attribute dissatisfaction with the results achieved to inappropriate learning strategies or their failure to manage learning resources effectively (Pintrich 2004; Zimmerman 2008). On the other hand, learners with less skilled selfcontrol, often fail to set goals and tend to pursue goals that keep them away from the task, show low self-confidence in learning and attribute unsatisfactory performance, especially from external sources, such as instructors or ineffectiveness learning design.

\section{Self-Regulated Learning in Online-Based Teacher Education and Training Programs}

Education and training to improve teacher competence and professionalism which has recently been transformed into online learning, besides having the advantages of flexibility in time and place, accessibility or broad reach, but in practice, it has many weaknesses and challenges. One of these weaknesses and challenges is a culture of selfregulated learning, the ability to learn independently (Marfuah 2017). For this reason, it is important for organizers and designers of online-based education and teacher training to consider providing features and facilities that support and foster self-regulated learning for their learning participants. In this case, Johnson explained that the technology in the digital learning environment that currently exists can encourage the implementation of the self-regulated learning cycle phase in learning, including 
understanding tasks and then planning, strategizing and evaluating the progress of completing the required tasks. Also in the digital learning environment, technology systems, curriculum materials and teaching procedures seek to improve self-regulated learning by providing mechanisms and opportunities for learners to clarify their understanding of tasks, develop effective plans, select strategies and monitor mastery of learning outcomes (Johnson and Davies 2014).

Technology has become an efficient means of enabling broad access to large and diverse content (Maldonado-Mahauad et al. 2018). When technology becomes closer and more familiar to each individual, at the same time the concept of self-regulated learning becomes very important in technology-based learning (Narciss, Proske, and Koerndle 2007). This is certainly related to how the technology used can maximize their learning success. In this context, self-regulated learning in terms of time management, metacognition, critical thinking, and efforts to manage to learn has a significant positive correlation with academic success in online learning (Broadbent and Poon 2015). There are at least three criteria that must be met by technology-enhanced learning environments to be able to support and grow self-regulated learning (Carneiro et al. 2011), namely: To begin, learners must be encouraged to arrange their learning activity to acquire planning and time management skills. Second, learners must receive proper feedback to track their progress. The communication method between the student and the teacher, as well as their classmates and the broader learning environment, is referred to as feedback. The technology in concern must be able to capture learner activities for the instructor or learning environment to provide appropriate feedback. Third, criteria should be provided to learners so that they may assess their learning results. Learners should be able to evaluate these results and draw conclusions that will guide future activities. To be able to do this, learners need to have or be given some criteria concerning their initial goals or concerning the competencies they are determined to achieve.

For various reasons, Barak noted, technology in learning has the potential to be one of the ideal platforms for fostering learner self-regulation behaviour. First, learning technology addresses issues that may stimulate learners' attention, stimulate their creativity, relate to everyday life, or serve the requirements of individuals and society, such as those of people with special needs. Second, learning technology puts the principle of "learning by doing" into practice, which has long been acknowledged by educators as an essential factor in the development of one's cognitive and social intelligence. Third, learning technology occurs in a rich learning environment that includes content, tools, instrumentation, and computers. Finally, when it comes to learning technology, students receive feedback not just from their professors and peers, but also from their successes and failures in designing, building, and solving problems (Barak 2010, 2018). According to Lock et al., it cannot be assumed that learners in an online environment will develop their self-regulation skills automatically and effectively. Instead, educators must create and maintain the development of selfregulation skills through rich learning experiences through deliberate design and facilitation efforts (Lock et al. 2017). As a result, self-regulated learning should be considered while designing online training. For teachers' professional development, online training should become a tool to support self-regulated learning. Teachers will be 
encouraged to provide their best efforts in teaching and learning if they have positive self-regulated learning profiles (Marfuah 2017).

\section{CONCLUSION}

Self-regulated learning is one of the important and strategic aspects for the success of every learner and online learning program. Along with the massive implementation of online-based teacher education and training programs, a major challenge arises for learners, namely their ability to learn effectively in these programs. This is because online-based teacher education and training programs are not like traditional learning settings. online-based teacher education and training programs require the involvement of every individual who learns. This is due to the lack of structured guidance and support that has been considered replaced by features in the technology or online learning platform they follow. To encourage effective learning in such an environment, every learner must be trained in mastering the key to selfregulated learning strategies. For this reason, every designer, organizer, and instructor needs to facilitate the development of aspects of self-regulated learning in their online learning platform. Although it cannot be assumed that they will automatically and effectively develop their self-regulated learning skills, through deliberate design and facilitation efforts, organizers and instructors need to create and sustain self-regulated learning skills development through rich learning experiences. The characteristics of teachers as participants with positive self-regulated learning tend to encourage the success of the online-based teacher education and training programs because teachers will give their best efforts to complete their online learning and have the potential to achieve the best results.

\section{REFERENCES}

Anderton, Betsy. 2006. "Using the Online Course to Promote Self-Regulated Learning Strategies in Preservice Teachers." Journal of Interactive Online Learning $5(2)$.

Barak, Miri. 2018. "Are Digital Natives Open to Change? Examining Flexible Thinking and Resistance to Change." Computers \& Education 121:115-23. doi: 10.1016/j.compedu.2018.01.016.

Barak, Moshe. 2010. "Motivating Self-Regulated Learning in Technology Education." International Journal of Technology and Design Education 20(4):381-401. doi: 10.1007/s10798-009-9092-x.

Broadbent, J., and W. L. Poon. 2015. "Self-Regulated Learning Strategies \& Academic Achievement in Online Higher Education Learning Environments: A Systematic Review." The Internet and Higher Education 27:1-13. doi: 10.1016/j.iheduc.2015.04.007.

Carneiro, Roberto, Paul Lefrere, Karl Steffens, and Jean D. M. Underwood. 2011. SelfRegulated Learning in Technology Enhanced Learning Environments: A European Perspective. Rotterdam; Boston: Sense.

Cheng, Gary, and Juliana Chau. 2013. "Exploring the Relationship between Students' Self-Regulated Learning Ability and Their EPortfolio Achievement." The Internet and Higher Education 17:9-15. doi: 10.1016/j.iheduc.2012.09.005. 
Cho, Moon-Heum, Yanghee Kim, and DongHo Choi. 2017. "The Effect of SelfRegulated Learning on College Students' Perceptions of Community of Inquiry and Affective Outcomes in Online Learning." The Internet and Higher Education 34:10-17. doi: 10.1016/j.iheduc.2017.04.001.

Dabbagh, Nada, and Anastasia Kitsantas. 2005. "Using Web-Based Pedagogical Tools as Scaffolds for Self-Regulated Learning." Instructional Science 33(56):513-40. doi: 10.1007/s11251-005-1278-3.

Dettori, Giuliana, Tania Giannetti, and Donatella Persico. 2006. "SRL in Online Cooperative Learning: Implications for Pre-Service Teacher Training." European Journal of Education 41(3-4):397-414. doi: 10.1111/j.14653435.2006.00273.x.

Dettori, Giuliana, and Donatella Persico, eds. 2011. Fostering Self-Regulated Learning through ICT. Hershey PA: Information Science Reference.

Hsiao, Hsien-Sheng, Chung-Chieh Tsai, Chien-Yu Lin, and Chih-Cheng Lin. 2012. "Implementing a Self-Regulated WebQuest Learning System for Chinese Elementary Schools." Australasian Journal of Educational Technology 28(2). doi: 10.14742/ajet.876.

Johnson, Genevieve M., and Sharon M. Davies. 2014. "Self-Regulated Learning in Digital Environments: Theory, Research, Praxis." British Journal of Research 1(2):14.

Kats, Yefim, ed. 2010. Learning Management System Technologies and Software Solutions for Online Teaching: Tools and Applications. IGI Global.

Kizil, Aysel ŞAHIN, and Zehra Savran. 2016. "Self-Regulated Learning In The Digital Age: An EFL Perspective." Novitas-ROYAL (Research on Youth and Language) 10(2):147-58.

Kumar, Sunil. 2015. "5 Common Problems Faced By Students In ELearning And How To Overcome Them - ELearning Industry." Retrieved November 10, 2021 (https://elearningindustry.com/5-common-problems-faced-by-students-inelearning-overcome).

Lock, Jennifer, Sarah Eaton, and Elaine Kessy. 2017. "Fostering Self-Regulation in Online Learning in K-12 Education." Northwest Journal of Teacher Education 12(2). doi: 10.15760/nwjte.2017.12.2.2.

Maldonado-Mahauad, Jorge, Mar Pérez-Sanagustín, René F. Kizilcec, Nicolás Morales, and Jorge Munoz-Gama. 2018. "Mining Theory-Based Patterns from Big Data: Identifying Self-Regulated Learning Strategies in Massive Open Online Courses." Computers in Human Behavior 80:179-96. doi: 10.1016/j.chb.2017.11.011.

Marfuah, Marfuah. 2017. "Profiling Self-Regulated Learning in Online Mathematics Teacher Training: A Case Study of a GeoGebra Course." Southeast Asian Mathematics Education Journal 7(1):45-55. doi: 10.46517/seamej.v7i1.44.

Narciss, Susanne, Antje Proske, and Hermann Koerndle. 2007. "Promoting SelfRegulated Learning in Web-Based Learning Environments." Computers in Human Behavior 23(3):1126-44. doi: 10.1016/j.chb.2006.10.006.

Nasir, M. 2005. Metode Penelitian Pustaka. 8th ed. Jakarta: Ghalia Indonesia. 
Perels, Franziska, Tina Gürtler, and Bernhard Schmitz. 2005. "Training of SelfRegulatory and Problem-Solving Competence." Learning and Instruction 15(2):123-39. doi: 10.1016/j.learninstruc.2005.04.010.

Pintrich, Paul R. 1999. "The Role of Motivation in Promoting and Sustaining SelfRegulated Learning." International Journal of Educational Research 31(6):459-70. doi: 10.1016/S0883-0355(99)00015-4.

Pintrich, Paul R. 2000. "The Role of Goal Orientation in Self-Regulated Learning." Pp. 451-502 in Handbook of Self-Regulation. Elsevier.

Pintrich, Paul R. 2004. "A Conceptual Framework for Assessing Motivation and SelfRegulated Learning in College Students." Educational Psychology Review 16(4):385-407. doi: 10.1007/s10648-004-0006-x.

Pintrich, Paul R., Akane Zusho, Ulrich Schiefele, and Reinhard Pekrun. 2001. "Goal Orientation and Self-Regulated Learning in the College Classroom: A Cross-Cultural Comparison." Pp. 149-69 in Student Motivation, edited by F. Salili, C. Y. Chiu, and Y. Y. Hong. Boston, MA: Springer US.

Prensky, Marc. 2004. "The Emerging Online Life of the Digital Native: What They Do Differently Because of Technology, and How They Do It." Https://Www.Marcprensky.Com.

Retrieved (https://www.marcprensky.com/writing/PrenskyThe_Emerging_Online_Life_of_the_Digital_Native-03.pdf).

Prensky, Marc. 2014. From Digital Natives to Digital Wisdom: Hopeful Essays for 21st Century Learning. Corwin Press.

Schunk, Dale H. 2012. Learning Theories: An Educational Perspective. 6th ed. Boston: Pearson.

Wang, Tzu-Hua. 2011. "Developing Web-Based Assessment Strategies for Facilitating Junior High School Students to Perform Self-Regulated Learning in an eLearning Environment." Computers \& Education 57(2):1801-12. doi: 10.1016/j.compedu.2011.01.003.

Winne, Philip H. 2015. "Self-Regulated Learning." Pp. 535-40 in International Encyclopedia of the Social \& Behavioral Sciences. Elsevier.

Winters, Fielding I., Jeffrey A. Greene, and Claudine M. Costich. 2008. "SelfRegulation of Learning within Computer-Based Learning Environments: A Critical Analysis." Educational Psychology Review 20(4):429-44. doi: 10.1007/s10648-008-9080-9.

Zed, Mestika. 2008. Metode Peneletian Kepustakaan. 2nd ed. Jakarta: Yayasan Obor Indonesia.

Zimmerman, Barry J. 2008. "Investigating Self-Regulation and Motivation: Historical Background, Methodological Developments, and Future Prospects." American Educational Research Journal 45(1):166-83. doi: 10.3102/0002831207312909.

Zimmerman, Barry J. 2015. "Self-Regulated Learning: Theories, Measures, and Outcomes." Pp. 541-46 in International Encyclopedia of the Social \& Behavioral Sciences. Elsevier. 